\title{
Role of Large Arteries in Regulation of Cerebral Blood Flow in Dogs
}

\author{
Donald D. Heistad, Melvin L. Marcus, and Francois M. Abboud, Cardiovascular \\ Division, Department of Internal Medicine and Cardiovascular Center, \\ University of Iowa College of Medicine, and Veterans Administration \\ Hospital, Iowa City, Iowa 52242
}

A B S T RAC T Previous studies have demonstrated a significant pressure gradient from carotid artery to pial or middle cerebral arteries. This pressure gradient suggests that large cerebral arteries contribute to cerebral resistance. We have tested the hypothesis that large cerebral arteries contribute to regulation of cerebral blood flow during changes in blood gases and arterial pressure. Microspheres were used to measure brain blood flow in anesthetized dogs. Resistance of large cerebral arteries was estimated by determining the pressure gradient between common carotid and wedged vertebral artery catheters. Systemic hypercapnia and hypoxia dilated large cerebral arteries, and hypocapnia constricted large cerebral arteries. Resistance of large arteries was $0.6 \pm 0.1($ mean $\pm \mathrm{SE}) \mathrm{mm} \mathrm{Hg}$ per $\mathrm{ml} / \mathrm{min}$ per $100 \mathrm{~g}$ during normocapnia. During hypercapnia and hypoxia, large artery resistance decreased significantly to $0.2 \pm 0.03$ and $0.3 \pm 0.05$, respectively. During hypocapnia large artery resistance increased significantly to $1.0 \pm 0.1$. In other experiments, we found that large cerebral arteries participate in autoregulatory responses to hemorrhagic hypotension. When arterial pressure was reduced from 110 to $58 \mathrm{~mm}$ $\mathrm{Hg}$, autoregulation maintained cerebral blood flow constant, and resistance of large cerebral arteries decreased significantly from $1.0 \pm 0.2$ to $0.6 \pm 0.1 \mathrm{~mm} \mathrm{Hg}$ per $\mathrm{ml} / \mathrm{min}$ per $100 \mathrm{~g}$. In absolute terms, we calculated that $20-45 \%$ of the change in total cerebral resistance during these interventions was accounted for by changes in large artery resistance. These studies indicate that large cerebral arteries, as well as arterioles, participate actively in regulation of cerebral blood flow during changes in arterial blood gases and during autoregulatory responses to hemorrhagic hypotension.

\section{INTRODUCTION}

The traditional concept is that arterioles rather than large arteries regulate cerebral vascular resistance. Two lines of evidence, however, suggest that large

Received for publication 20 June 1977 and in revised form 25 May 1978. arteries may serve an important resistance function in the cerebral circulation. First, there is a significant pressure gradient along large arteries that supply the brain (1-7). For example, when systemic arterial pressure is $100 \mathrm{~mm} \mathrm{Hg}$ in cats, pressure in pial arteries $300 \mu \mathrm{m}$ in diameter is about $70 \mathrm{~mm} \mathrm{Hg}(7)$. The pressure gradient varies in proportion with changes in systemic arterial pressure (5-7). Second, arteriographic findings suggest that the diameter of large cerebral arteries varies during changes in arterial pressure (8) and blood gases (9). Although these studies suggest that large cerebral arteries participate in regulation of cerebral vascular resistance and blood flow, they do not provide a quantitative assessment of the relative contribution of large arteries to total cerebral vascular resistance.

If large arteries do contibute to regulation of cerebral blood flow, this could have important implications in patients with cerebrovascular disease. Pathological changes of large arteries, even in the absence of critical stenosis, would limit their capacity to maintain flow during hypotension or to increase blood flow during hypoxia. It is also possible that constriction of large cerebral arteries could convert a hemodynamically unimportant lesion to a critical narrowing. A similar hypothesis has been proposed for coronary vessels (10).

The purpose of this study was to determine whether large arteries participate in regulation of cerebral vascular resistance during changes in systemic arterial pressure and arterial blood gases. Resistance of cerebral arteries was determined by measuring cerebral blood flow with microspheres and by measuring the gradient between common carotid artery pressure and vertebral artery wedge pressure (11). We tested the hypotheses that the resistance of large cerebral arteries is altered during changes in arterial $\mathrm{P}_{\mathrm{CO}_{2}}$ and $\mathrm{P}_{\mathrm{O}_{2}}$ and that large cerebral arteries participate in the autoregulatory response to hemorrhagic hypotension.

\section{METHODS}

Animal preparation. 32 mongrel dogs weighing $18-29 \mathrm{~kg}$ were anesthetized with chloralose $(50 \mathrm{mg} / \mathrm{kg})$ and urethane $(500 \mathrm{mg} / \mathrm{kg})$ and artificially ventilated with room air and 
supplemental oxygen. Polyethylene catheters were inserted into a thyroid artery for measurement of systemic arterial pressure, a brachial and femoral artery for withdrawal of arterial blood samples, a brachial vein for drug administration, and the left atrial appendage for injection of microspheres. Heparin (500 U/kg, i.v.) and decamethonium bromide $(0.3 \mathrm{mg} /$ $\mathrm{kg}$, i.v.) were given for anticoagulation and skeletal muscle paralysis, respectively. Arterial blood gases and $\mathrm{pH}$ were frequently measured (model 113, Instrumentations Laboratory, Inc., Lexington, Mass.) throughout each experiment.

Measurement of cerebral blood flow. Radioactive microspheres (Minnesota Mining \& Manufacturing, St. Paul, Minn.) having a mean diameter of $15 \mu \mathrm{m}$ were used. We injected microspheres labeled with four of these five isotopes, ${ }^{6} \mathrm{Sc}$, ${ }^{95} \mathrm{Nb},{ }^{85} \mathrm{Sr}$, ${ }^{141} \mathrm{Ce}$, or ${ }^{125} \mathrm{I}$, which allowed us to make as many as four separate determinations of cerebral blood flow during each experiment. Before injection, the vial containing the microspheres, suspended in $10 \%$ dextran with one drop of Tween-80 (ICI United States, Inc., Wilmington, Del.), was vigorously shaken for 3 min on a Vortex mixer. 3-6 million microspheres were slowly injected over a 20 -s period and flushed with $10 \mathrm{ml}$ of warm saline. Beginning $30 \mathrm{~s}$ before injection of the microspheres, and continuing for 2 min after injection, reference blood samples were withdrawn at the rate of $2.06 \mathrm{ml} / \mathrm{min}$ from the brachial and femoral arterial catheters. The interval between each microsphere injection was 10-30 min.

At the end of each experiment, the brain was excised and dissected into regional samples: medulla and pons (brainstem), thalamus-midbrain, cerebellum, and cerebrum. Temporalis muscle samples were also obtained. The brain and muscle samples weighed $0.3-4.0 \mathrm{~g}$.

The tissue and reference blood samples were placed in plastic test tubes and counted in a 3-inch well-type gamma counter. The energy windows for ${ }^{46} \mathrm{Sc},{ }^{95} \mathrm{Nb},{ }^{85} \mathrm{Sr},{ }^{141} \mathrm{Ce}$, and ${ }^{125} \mathrm{I}$ were $800-1,500,650-800,400-525,125-175$, and $20-50$ $\mathrm{keV}$, respectively. Separation of the isotopes was accomplished using differential spectroscopy by the method of Rudolph and Heyman (12).

Output from the gamma counter was punched on tape for subsequent computer processing. We calculated cerebral blood flow by the equation $\mathrm{CBF}=\mathrm{C}_{\mathrm{B}} \times 100 \times \mathrm{RBF} \div \mathrm{C}_{\mathrm{R}}$, where $\mathrm{CBF}=$ cerebral blood flow in milliliters per minute per $100 \mathrm{~g}, \mathrm{C}_{\mathrm{B}}=$ counts per gram of brain, $\mathrm{RBF}=$ reference blood flow (rate of withdrawal of blood samples from reference arteries), and $C_{R}=$ total counts in the reference arterial blood samples. The counts in the two reference arterial bloods were averaged for the flow calculation. Muscle blood flow was determined by similar calculations.

Measurement of large artery responses. Both vertebral arteries were exposed using the technique of Rapela and Martin (11). Large catheters (polyethylene 200) were advanced until they wedged in the vertebral arteries, then smaller catheters (polyethylene 50) were inserted through the large catheters until they wedged in the vertebral arteries at about the level of C-2 (Fig. 1). During bilateral carotid occlusion, vertebral artery pressure decreased to about $30 \mathrm{~mm}$ $\mathrm{Hg}$. The marked reduction in pressure suggests that, with the vertebral arteries occluded, almost all of the blood flow to the brain is through the carotids, and collateral flow is minimal ( 11 , 13). The preparation was considered unsatisfactory, and the experiment was terminated if the pressure obtained during carotid occlusion was $>35 \mathrm{~mm} \mathrm{Hg}$ or if the catheters were not located above $\mathrm{C}-3$ at postmortem examination. In three dogs that we studied, carotid occlusion caused a typical decrease in pressure in one vertebral artery but no reduction in pressure in the other vertebral artery. In these three dogs the vertebral artery catheter on the side that did not respond to carotid

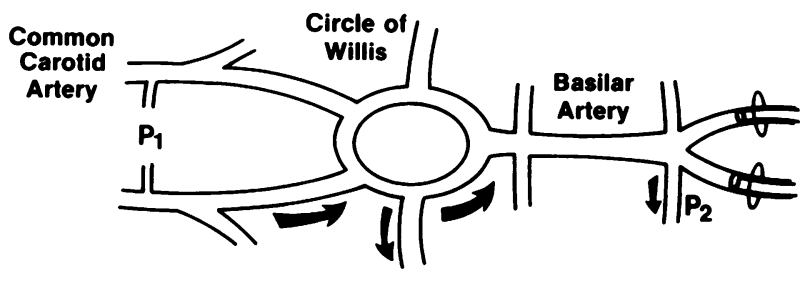

FIgure 1 Technique of Rapela and Martin (11) for measurement of pressure gradient along large cerebral arteries. When both vertebral arteries are occluded by catheters, blood flow to the brain is through the carotid arteries in the direction indicated by the arrows. Pressure is measured in the carotid artery $\left(P_{1}\right)$ and the wedged vertebral artery catheter $\left(P_{2}\right)$. The pressure gradient between carotid and vertebral artery $\left(P_{1}-P_{2}\right)$ is divided by cerebral blood flow to calculate resistance of large arteries.

occlusion was wedged in a branch of the vertebral artery, and the catheter on the "responsive" side was in the appropriate position in the vertebral artery. In those three dogs, we used vertebral artery pressure obtained on the "responsive" side. In the other dogs, there was a 2-6 $\mathrm{mm} \mathrm{Hg}$ difference in pressure between the two sides, and responses to carotid occlusion and interventions were similar on the two sides. In these dogs, we calculated vertebral artery wedge pressure from the side that had the higher initial pressure.

The gradient in pressure between the common carotid artery (measured with the catheter in the thyroid artery) and wedged vertebral arteries reflects the resistance of the large arteries that supply the brain $(11,13)$. Large cerebral artery resistance was calculated by dividing the pressure gradient by total cerebral blood flow.

With this technique, the resistance of large arteries that supply the brain is determined by the carotid arteries, the circle of Willis (posterior communicating and posterior celebral arteries), the basilar artery, and the vertebral arteries. To determine whether the posterior communicating arteries contribute disproportionately to resistance in this preparation, we measured the diameter of the major intracranial arteries in three dogs. After the dogs were killed, a partially polymerized monomer (Batson's 17 anatomical corrosion compound, Polysciences, Inc., Warrington, Pa.) was infused at $7.5 \mathrm{ml} / \mathrm{min}$ into each common carotid and vertebral artery (total $=30 \mathrm{ml} /$ $\mathrm{min}$ for $2 \mathrm{~min}$ ). After the mixture polymerized to a solid, the soft tissues were dissolved, and the inner diameter of the arteries was measured with a micrometer. The mean diameter ( $\pm 1 \mathrm{SE})$ for the internal carotid, posterior communicating, posterior cerebral (in circle of Willis), and basilar arteries was $1.7 \pm 0.2,1.0 \pm 0.1,1.2 \pm 0.2$, and $1.3 \pm 0.2 \mathrm{~mm}$, respectively. The diameter of the posterior communicating was $74 \pm 7 \%$ of the diameter of the basilar artery, in contrast to man in whom the relative diameter of the two vessels is only $27 \%$ (14; derived from Table 58-2). Our approach to fixation of vessels does not allow precise estimation of vascular caliber in vivo. It appears, however, that the posterior communicating artery contributes importantly, but not disproportionately, to resistance in this experimental preparation.

In two dogs we attempted to determine whether the phasic characteristics of the vertebral artery pressure tracing changed during the interventions. The tracings obtained for systemic and vertebral arterial pressure were compared during control conditions, hypercapnia, and hypocapnia. Changes in pulse pressure and configuration of the two tracings were similar during the interventions.

We considered the possibility that calculations of large 
artery resistance might reflect responses in the extracranial muscle circulation as well as the cerebral vasculature. For example, if there were a significant pressure gradient in the extracranial arteries that supply the brain, reduction in flow to muscle supplied by branches of the extracranial arteries might reduce the pressure gradient. As a result, our values for large cerebral artery gradient and resistance would be artifactually reduced. To test this possibility, norepinephrine was infused into both common carotid arteries while measuring pressure in the vertebral arteries and in the carotid artery. Norepinephrine reduces flow to extracranial tissue but does not constrict cerebral vessels (15), presumably because access to receptors is limited by the blood-brain barrier.

Intracarotid infusion of norepinephrine $(2.5 \mu \mathrm{g} / \mathrm{min}$ as the base) in five dogs did not alter systemic arterial pressure or the pressure gradient from carotid to vertebral arteries, did not reduce cerebral blood flow, and did not affect calculated large artery resistance. The gradient from common carotid to vertebral artery was $18 \pm 3.7$ and $17 \pm 3.2 \mathrm{~mm} \mathrm{Hg}$ during control and norepinephrine infusion, respectively. Blood flow to the brain was $32 \pm 2.7$ and $42 \pm 4.0 \mathrm{ml} / \mathrm{min}$ per $100 \mathrm{~g}$ during control and intracarotid infusion of norepinephrine, respectively $(P>0.05)$. Blood flow in the masseter and temporal muscles decreased from $13 \pm 4.5 \mathrm{ml} / \mathrm{min}$ per $100 \mathrm{~g}$ during control to $5 \pm 1.7 \mathrm{ml} / \mathrm{min}$ per $100 \mathrm{~g}$ during norepinephrine infusion $(P<0.05)$. These results indicate that reduction in muscle blood flow does not alter values obtained for large artery resistance.

We examined the potential role of collateral vessels to the brain in this preparation in two ways. First, vertebral artery pressure during bilateral carotid occlusion was measured in three dogs during the control period, hypercapnia and hypocapnia. If the response to carotid occlusion were variable, this would suggest that collateral flow to the brain in this preparation is variable. Vertebral artery pressure during carotid occlusion was $27 \pm 3 \mathrm{~mm} \mathrm{Hg}$ during hypercapnia, $24 \pm 5$ during control, and $27 \pm 5$ during hypocapnia. The data suggest that collateral flow is not variable during the interventions.

Second, collateral blood flow was quantitated directly in six dogs by perfusing both carotid arteries with blood that did not contain microspheres. Catheters were wedged in both vertebral arteries in the usual way, and microspheres were injected into the left atrium during this control period. Catheters were then inserted into both common carotid arteries, and arterial blood was perfused from a reservoir at constant flow. Blood flow was adjusted to maintain carotid perfusion pressure similar to systolic arterial pressure. Microspheres were then injected into the left atrium while inflow into the carotid perfusion reservoir was stopped, but perfusion of the carotid arteries continued. Thus, microspheres could not reach the brain through the carotid or vertebral arteries, and we were able to measure collateral blood flow to the brain. About 3 min later, inflow to the reservoir was reinstituted, and systemic hypercapnia was begun. Arterial $\mathrm{P}_{\mathrm{CO}_{2}}$ was increased from $41 \pm 1.7$ to $75 \pm 2.4 \mathrm{~mm} \mathrm{Hg}$. Microspheres were injected while inflow into the carotid perfusion reservoir was stopped, but perfusion of the carotid arteries continued.

During the control period, blood flow to the brain was $34 \pm 3$ $\mathrm{ml} / \mathrm{min}$ per $100 \mathrm{~g}$. Collateral blood flow was $4 \pm 2$ and $3 \pm 2 \mathrm{ml} /$ min per $100 \mathrm{~g}$ during normocapnia and hypercapnia, respectively. These experiments provide evidence that collateral blood flow to the brain is minimal in this preparation during normal conditions and during hypercapnia.

Alteration of systemic arterial pressure and blood gases. We studied responses to selective alteration of arterial carbon dioxide and oxygen levels in nine dogs. Hypercapnia was induced in eight dogs by adding a mixture of $10 \% \mathrm{CO}_{2}$ in nitrogen, at flow rates of 2-7 liters $/ \mathrm{min}$, to the inspired room air, with supplemental $100 \% \mathrm{O}_{2}$ to maintain normoxia. Hypocapnia was produced in nine dogs by increasing the respiratory rate. Hypoxia was produced by ventilating eight dogs with $10 \% \mathrm{O}_{2}$ in nitrogen. Flow measurements were obtained four times during each experiment: a control period, hypercapnia, hypocapnia, and hypoxia. The order of these periods was randomized.

Responses to hypotension were examined in 10 dogs. Hypotension was induced by bleeding the animals until arterial pressure was about 90 and $60 \mathrm{~mm} \mathrm{Hg}$. At each level of arterial pressure, an equilibration period of 10-15 min was allowed before microspheres were injected. Blood flow was measured during a control period, at the two levels of hypotension, and during a recovery period, when the animals arterial pressure was restored to normal by intravenous injection of blood and small amounts of $10 \%$ dextran when necessary. In one dog measurements were not obtained during the initial control period, and in one dog measurements were not obtained during the recovery period. Arterial blood gases and pH were determined at each level of arterial pressure before and after injection of microspheres. Blood gases and $\mathrm{pH}$ were maintained at normal by adjustments in ventilation or injections of small volumes of sodium bicarbonate.

Statistical analysis was performed using analysis of variance. Where a significant treatment effect was found, Tukey's multiple comparison test (16) was used to detect significant differences $(P<0.05)$ between any two groups.

\section{RESULTS}

Effects of alterations in systemic blood gases. Systemic hypercapnia, hypocapnia, and hypoxia altered total cerebral blood flow and resistance of large cerebral arteries. Hypercapnia produced a marked increase in cerebral blood flow, a large decrease in total cerebral resistance, and a decrease in large artery resistance (Table I). Responses to hypoxia were similar, in that the fractional decrease in total cerebral resistance and large artery resistance was similar. Systemic hypocapnia produced a marked reduction in cerbral flow and a significant increase in total cerebral resistance and large artery resistance (Fig. 2). These observations indicate that large cerebral arteries are responsive to changes in systemic blood gases.

Hypercapnia and hypoxia reduced blood flow to cranial muscle (Table I), presumably by activating arterial chemoreceptors. Hypocapnia did not affect muscle blood flow.

Effects of alterations in systemic arterial pressure. Systemic hypotension did not alter total or regional cerebral blood flow; i.e., cerebral vasodilation maintained normal perfusion to the brain (Table II). In contrast, there was a marked reduction in muscle blood flow during hypotension.

Total cerebral vascular resistance decreased in proportion to the decrease in systemic arterial pressure. Large cerebral arteries appeared to participate in the vasodilator response to hypotension. Reductions of systemic pressure to $\cong 80$ and $50 \%$ of control were accompanied by proportional decreases in large cerebral artery vasçular resistance (Fig. 3 ). These measure- 
TABLE I

Effect of Alterations in Systemic Blood Gases on Large Artery Resistance and Cerebral Blood Flow*

\begin{tabular}{|c|c|c|c|c|}
\hline & Control & Hypercapnia & Hypocapnia & Hypoxia \\
\hline Total cerebral blood flow, $\mathrm{ml} / \mathrm{min}$ per $100 \mathrm{~g}$ & $47 \pm 7.8$ & $116 \pm 15.8$ & $22 \pm 1.8$ & $88 \pm 17.8 \ddagger$ \\
\hline Mean arterial pressure, $\mathrm{mm} \mathrm{Hg}$ & $106 \pm 3.6$ & $89 \pm 5.1$ & $98 \pm 5.8$ & $104 \pm 7.5$ \\
\hline $\begin{array}{l}\text { Total cerebral vascular resistance, } \\
\qquad \mathrm{mm} \mathrm{Hg} \text { per } \mathrm{ml} / \mathrm{min} \text { per } 100 \mathrm{~g}\end{array}$ & $2.4 \pm 0.3$ & $0.8 \pm 0.1 \ddagger$ & $4.6 \pm 0.5 \ddagger$ & $1.6 \pm 0.4 \ddagger$ \\
\hline $\begin{array}{l}\text { Large artery pressure gradient, } m m \mathrm{Hg} \S \\
\text { Large artery resistance, }\end{array}$ & $23 \pm 2.9$ & $21 \pm 2.8$ & $20 \pm 2.6$ & $20 \pm 3.5$ \\
\hline $\begin{array}{l}\mathrm{mm} \mathrm{Hg} \text { per } \mathrm{ml} / \mathrm{min} \text { per } 100 \mathrm{~g} \S \\
\text { Systemic blood gases and } \mathrm{pH}\end{array}$ & $0.64 \pm 0.06$ & $0.19 \pm 0.03 \ddagger$ & $0.95 \pm 0.14 \ddagger$ & $0.26 \pm 0.05$ \\
\hline $\begin{array}{l}\mathrm{Pa}_{\mathrm{CO}_{2}}, m m H g \\
\mathrm{pH} \\
\mathrm{Pa}_{\mathrm{O}_{2}}, m m H g\end{array}$ & $\begin{array}{c}38 \pm 0.6 \\
7.37 \pm 0.01 \\
134 \pm 10.8\end{array}$ & $\begin{array}{c}56 \pm 2.8 \\
7.21 \pm 0.01 \\
125 \pm 15.0\end{array}$ & $\begin{array}{c}21 \pm 0.7 \\
7.55 \pm 0.02 \\
119 \pm 4.0\end{array}$ & $\begin{array}{c}37 \pm 0.9 \\
7.37 \pm 0.01 \\
30 \pm 2.3\end{array}$ \\
\hline $\begin{array}{l}\text { Temporal muscle blood flow, } \\
\text { ml/min per } 100 \mathrm{~g} \\
\text { Regional cerebral blood flow, } \\
\text { ml/min per } 100 \mathrm{~g}\end{array}$ & $13 \pm 2.8$ & $6 \pm 1.4 \rrbracket$ & $12 \pm 3.2$ & $6 \pm 1.1 \ddagger$ \\
\hline Cerebrum & $46 \pm 6.2$ & $111 \pm 18.5$ & $22 \pm 1.9$ & $87 \pm 18.2$ \\
\hline Cerebellum & $59 \pm 9.3$ & $140 \pm 11.6$ & $25 \pm 1.8$ & - $94 \pm 16.6$ \\
\hline Thalamus-midbrain & $42 \pm 5.7$ & $135 \pm 13.4$ & $22 \pm 2.1$ & $93 \pm 19.4$ \\
\hline Brainstem & $42 \pm 6.1$ & $126 \pm 12.3$ & $20 \pm 1.7$ & $90 \pm 18.9$ \\
\hline Number of dogs & 9 & 8 & 9 & 8 \\
\hline
\end{tabular}

* Results are expressed as mean $\pm \mathrm{SE}$.

\$ Values are significantly different from control values by analysis of variance and Tukey's test $(P<0.05)$.

$\$$ Large artery pressure gradient was calculated as the difference between mean systemic (common carotid) and wedged vertebral artery pressure. Large artery resistance was calculated by dividing large artery pressure gradient by total cerebral blood flow.

ments indicate that large cerebral arteries have an important dilator capacity that is activated by systemic hypotension.

\section{DISCUSSION}

This study indicates that large arteries participate in cerebral vascular responses to changes in systemic blood gases and arterial pressure. It appears that large cerebral arteries provide significant resistance to blood flow, they can dilate during hypercapnia or hypoxia, and they can constrict during hypocapnia. During alterations in blood gases, the fractional change in large artery resistance and total cerebral resistance is similar, which suggests that responsiveness of large arteries and arterioles to these stimuli is similar. Large arteries also participated in the autoregulatory response to hypotension.

In this study we used the technique of Rapela and Martin (11) to estimate resistance of large arteries that supply the brain. We have considered several questions which relate to the technique.

First, does the pressure in the wedged vertebral artery catheter indicate vertebral artery pressure or, because of communications with extracranial vessels, does it reflect systemic arterial pressure? Heistad et al. (13), as well as Rapela and Martin (11), have observed a marked decrease in vertebral wedge pressure during bilateral carotid occlusion, despite increases in systemic arterial pressure. This finding suggests that vertebral wedge pressure reflects vertebral artery, rather than systemic arterial, pressure.

Second, do changes in blood flow to extracranial

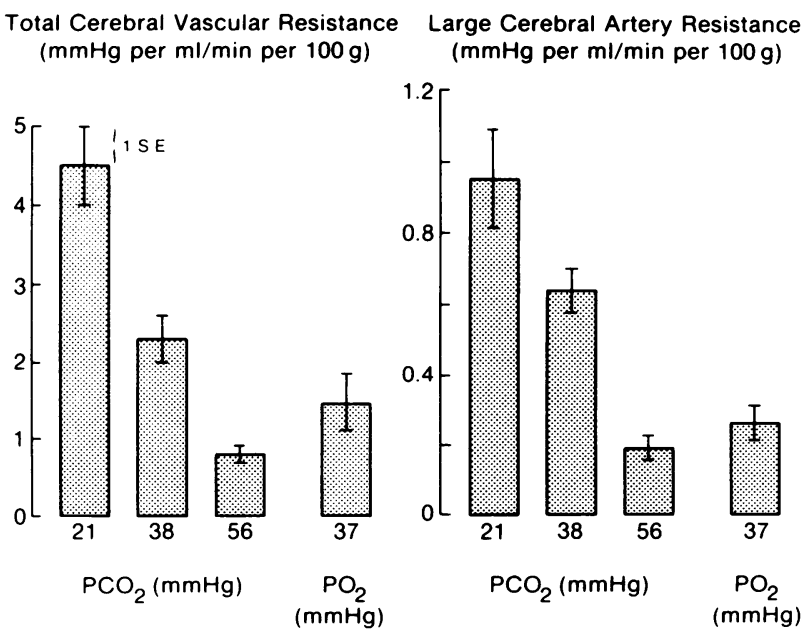

FIGURE 2 Effect of hypocapnia, hypercapnia, and hypoxia on total cerebral vascular resistance and resistance of large arteries. The scale is different in the two panels. 
TABLE II

Effect of Hemorrhagic Hypotension on Large Artery Resistance and Cerebral Blood Flow*

\begin{tabular}{|c|c|c|c|c|}
\hline & Control & Hypotension 1 & Hypotension 2 & Recovery \\
\hline Total cerebral blood flow, $\mathrm{ml} / \mathrm{min}$ per $100 \mathrm{~g}$ & $39 \pm 5.0$ & $38 \pm 3.9$ & $39 \pm 3.6$ & $36 \pm 4.2$ \\
\hline $\begin{array}{l}\text { Mean arterial pressure, } \mathrm{mm} \mathrm{Hg} \\
\text { Total cerebral vascular resistance, }\end{array}$ & $110 \pm 2.4$ & $87 \pm 2.6$ & $58 \pm 1.1$ & $109 \pm 2.5$ \\
\hline $\mathrm{mm} \mathrm{Hg}$ per $\mathrm{ml} / \mathrm{min}$ per $100 \mathrm{~g}$ & $3.2 \pm 0.4$ & $2.5 \pm 0.3 \ddagger$ & $1.6 \pm 0.2 \ddagger$ & $3.5 \pm 0.5$ \\
\hline $\begin{array}{l}\text { Large artery pressure gradient, } m m \mathrm{Hg} \S \\
\text { Large artery resistance, }\end{array}$ & $34 \pm 2.5$ & $26 \pm 2.4 \ddagger$ & $21 \pm 2.2 \ddagger$ & $33 \pm 3.0$ \\
\hline $\begin{array}{l}\mathrm{mm} \mathrm{Hg} \text { per ml/min per } 100 \mathrm{~g} \S \\
\text { Systemic blood gases and pH }\end{array}$ & $1.0 \pm 0.2$ & $0.8 \pm 0.1$ & $0.6 \pm 0.1 \ddagger$ & $1.0 \pm 0.2$ \\
\hline $\mathrm{P}_{\mathrm{CO}_{2}}$ & $37 \pm 0.50$ & $36 \pm 0.25$ & $37 \pm 0.51$ & $38 \pm 0.56$ \\
\hline $\mathrm{pH}$ & $7.37 \pm 0.01$ & $7.37 \pm 0.01$ & $7.35 \pm 0.01$ & $7.35 \pm 0.01$ \\
\hline$P_{\mathrm{O}_{2}}$ & $129 \pm 9.6$ & $125 \pm 8.2$ & $124 \pm 7.3$ & $133 \pm 6.7$ \\
\hline $\begin{array}{l}\text { Temporal muscle blood flow, } \\
\text { ml/min per } 100 \mathrm{~g} \\
\text { Regional cerebral blood flow, } \\
\text { ml/min per } 100 \mathrm{~g}\end{array}$ & $19 \pm 5.0$ & $7 \pm 2.3 \ddagger$ & $3 \pm 0.6 \ddagger$ & $17 \pm 4.1$ \\
\hline Cerebrum & $38 \pm 5.1$ & $37 \pm 4.2$ & $38 \pm 3.6$ & $36 \pm 4.7$ \\
\hline Cerebellum & $47 \pm 5.5$ & $50 \pm 6.1$ & $45 \pm 4.2$ & $43 \pm 5.2$ \\
\hline Thalamus-midbrain & $37 \pm 3.9$ & $38 \pm 4.1$ & $39 \pm 3.7$ & $36 \pm 4.1$ \\
\hline Brainstem & $37 \pm 3.9$ & $38 \pm 4.3$ & $38 \pm 3.7$ & $35 \pm 4.3$ \\
\hline Number of dogs & 9 & 10 & 10 & 9 \\
\hline
\end{tabular}

* Results are expressed as mean $\pm \mathrm{SE}$.

\$ Values are significantly different from control values by analysis of variance and Tukey's test $(P<0.05)$. $\$$ Large artery pressure gradient was calculated as the difference between mean systemic (common carotid) and wedged vertebral artery pressure. Large artery resistance was calculated by dividing large artery pressure gradient by total cerebral blood flow.

tissues affect the values calculated for resistance of large cerebral arteries? We found that norepinephrine, which reduces flow to extracranial muscle without reducing cerebral blood flow, does not alter the calculated resistance of large cerebral arteries. This finding suggests that the vasoconstriction in muscle observed during hypercapnia, hypoxia, and hypotension did not artifactually account for the changes in large cerebral artery resistance which were observed.

Third, is the value calculated for large artery resistance a precise determination? Large artery resistance is determined by dividing the pressure gradient of the large arteries by total blood flow to the brain. Although both the pressure gradient and blood flow can be measured accurately, the calculation of resistance is not precise. This calculation assumes that all of the blood flow to the brain traverses the large cerebral arteries from the carotid to the vertebral arteries. Because only a portion of the brain blood flow traverses the length of these arteries, our calculation must underestimate large artery resistance. A critical question is whether this underestimation of resistance is variable and might account for the changes we observed. For example, if hypercapnia redistributed blood flow to favor the cerebrum rather than cerebellum and brainstem, a smaller fraction of flow would traverse the length of the large cerebral arteries to the vertebral artery catheters. Large artery resistance would then be underestimated, and this change could account for our finding. However, hypercapnia and the other interventions that we studied did not redistribute flow between major regions of the brain. Thus, this factor cannot account for our findings.

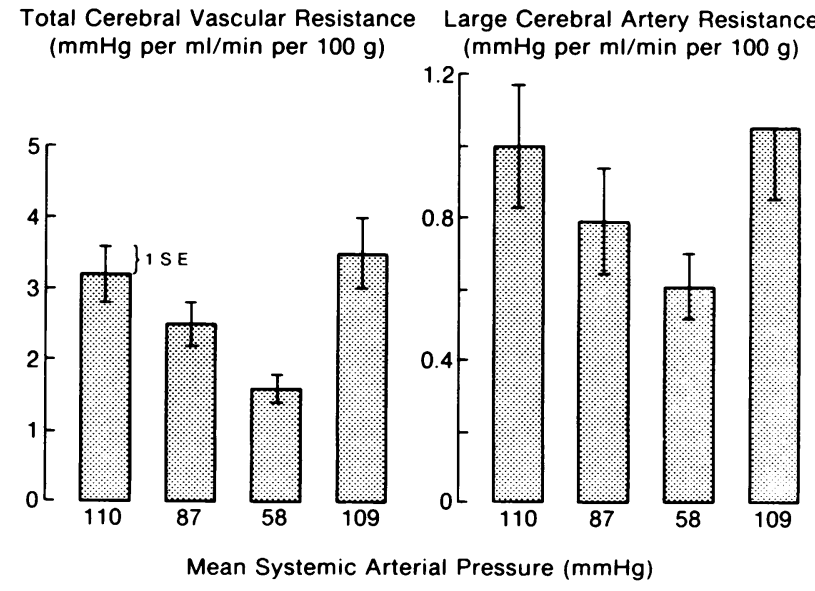

FIGURE 3 Effect of hemorrhagic hypotension on total cerebral vascular resistance and resistance of large arteries. 
It also is not possible to calculate the energy dissipated by nonlaminar flow or by changes in mechanical properties of the vessel wall. It is likely that the energy loss from nonlaminar flow is minimal, because the Reynolds number in cerebral vessels must be far below the critical value of 2,000. Similarly, the contribution of the pulsatile component to the loss of total hydraulic power, and its modification by changes in the vessel wall, must be small: the small size of cerebral vessels and the fact that flow occurs during both systole and diastole would minimize the pulsatile component.

Fourth, does occlusion of both vertebral arteries affect the responses that were observed? It is clear that responses to changes in blood gases and autoregulatory responses were preserved despite vertebral artery occlusion. We should point out, however, that the pressure gradient across large arteries must be somewhat exaggerated in this preparation. Because the carotid arteries are carrying both their normal blood flow and the flow that normally passes through the vertebral arteries, the pressure gradient across these vessels must be accentuated.

Several studies have indicated that there is an important pressure gradient across the arteries between the aorta and large arteries of the brain (1-7). These studies suggested that large arteries, as well as arterioles, are resistance vessels in the brain. Furthermore, because the pressure gradient varied as arterial pressure changed (5-7), the experiments suggested that resistance of large arteries is not constant. Arteriographic studies $(8,9,17)$ and measurement of diameter of large pial arteries (18) also lead to the conclusion that large arteries play an important role in regulation of cerebral blood flow. An interesting observation is that large $(>100 \mu \mathrm{m})$ but not small $(<60 \mu \mathrm{m})$ pial arteries dilate when arterial pressure is reduced from 120 to 80 $\mathrm{mm} \mathrm{Hg}$ in cats (18). Small arteries (40-90 $\mu \mathrm{m})$ have also been reported (19) to dilate during hypercapnia, although not as much as arterioles $(13-40 \mu \mathrm{m})$. These studies provide strong support for the concept that large arteries participate in regulation of cerebral blood flow; however, as blood flow was not measured in these studies, it is not possible to estimate quantitatively the changes in resistance.

Recent studies by Rapela and Martin (11) and by Heistad et al. (13) provide quantitative estimates of changes in resistance of large arteries that supply the brain. These previous studies indicate that serotonin produces marked constriction of large arteries $(11,13)$ and that stimulation of sympathetic nerves does not constrict large arteries to a sufficient degree to produce detectable hemodynamic effects (13).

Fukasawa (20) has performed a theoretical analysis of the site of resistance in cerebral arteries, based on acrylic casts of arteries in the human brain. The calculations suggest that the major pressure drop occurs in the large arteries, and they suggest a relatively minor role for intraparenchymal arteries and arterioles. These calculations must be interpreted cautiously, but they emphasize the potential role of large arteries as resistance vessels.

We should consider the relative contribution of large arteries to regulation of total cerebral vascular resistance. Large artery resistance increased from $0.19 \mathrm{U}$ during hypercapnia to $0.95 \mathrm{U}$ during hypocapnia, whereas the corresponding change in total cerebral vascular resistance was from 0.8 to $4.6 \mathrm{U}$ (Table I). In absolute terms, $20 \%$ of the change in total resistance during changes in arterial $\mathrm{P}_{\mathrm{CO}_{2}}$ was accounted for by the change in large artery resistance. Similar calculations suggest that $47 \%$ of the change in total resistance during hypoxia, and $25 \%$ of the change in total resistance during hypotension, was accounted for by the change in large artery resistance. The calculations, although not precise, emphasize the quantitative importance of large arteries in the regulation of cerebral vascular resistance. Furthermore, we determined resistance only in very large arteries: the carotid arteries, circle of Willis, and basilar arteries. If our findings can be extrapolated to smaller cerebral arteries, then the relative contribution of large and small cerebral arteries to cerebral resistance becomes even greater, and the contribution of cerebral arterioles becomes smaller.

What is the mechanism for the change in large artery resistance during changes in blood gases and arterial pressure? We have no direct evidence to answer this question, but we would like to speculate about possible mechanisms. Neural mechanisms seem unlikely because we have been unable to detect effects of chemoreceptors (21) or baroreceptors (22) on cerebral vessels. Recent evidence (23) supports the traditional view that local factors entirely account for the response of cerebral arterioles to changes in $\mathrm{CO}_{2}$. It seems likely that similar mechanisms, mediated by changes in arterial $\mathrm{CO}_{2}$ and $\mathrm{pH}$ of cerebrospinal fluid, account for the response of large arteries to changes in $\mathrm{CO}_{2}$.

The mechanism of the autoregulatory response to hypotension may be more complex. The relative contribution of two general mechanisms, the myogenic and metabolic, remains controversial. Preliminary observations by Kontos (18) are of considerable interest. He reported that reductions in arterial pressure from 120 to $80 \mathrm{~mm} \mathrm{Hg}$ dilated large but not small pial arteries, but small arteries dilated more than large arteries with further reductions in pressure. It is possible that the autoregulatory response of large arteries is primarily myogenic, and during severe hypotension a primarily metabolic autoregulatory response of arterioles assumes greater importance.

The concept that large arteries play an important role in the regulation of blood flow has received atten- 
tion, not only in relation to control of cerebral blood flow, but also in regulation of flow in other vascular beds. Sympathetic nerve stimulation and serotonin constrict large arteries in the forelimb of dogs (24, 25 ), and the diving reflex constricts large arteries in the flipper of seals (26) and forearm of man (27). Preliminary observations suggest that coronary arteries, as well as arterioles, contribute importantly to coronary vascular resistance (28). The authors estimated that $16 \%$ of coronary perfusion pressure is dissipated by arteries larger than $150 \mu \mathrm{m}$ in diameter and that resistance vessels $24-150 \mu \mathrm{m}$ in diameter account for $36 \%$ of the total pressure drop. Nitroglycerine appears to dilate preferentially large coronary arteries, in contrast to dipyridamole which may dilate preferentially small coronary arteries (29). Preliminary observations suggest that large resistance vessels may participate in autoregulation of blood flow in skeletal muscle (30). The caliber of resistance vessels $100 \mu \mathrm{m}$ in diameter increased $40 \%$ when arterial pressure was reduced from 120 to $80 \mathrm{~mm} \mathrm{Hg}$, and the caliber of arterioles $20 \mu \mathrm{m}$ in diameter increased only $25 \%$ when arterial pressure was reduced from 120 to $60 \mathrm{~mm} \mathrm{Hg}$. All of these studies suggest that large and small arteries, as well as arterioles, contribute to regulation of blood flow in several vascular beds.

We would like to speculate about the possible clinical significance of our observations, and to draw an analogy with regulation of coronary blood flow. These studies suggest that large arteries play an important role in the regulation of cerebral blood flow. It is likely that atherosclerotic changes in large cerebral arteries limit the ability of large cerebral vessels to dilate during hypotension or hypoxia. If this is the case, atherosclerotic changes could increase the susceptibility to cerebral ischemia even without encroaching significantly on the vascular lumen. Furthermore, in vessels with moderate, but not critical, atherosclerotic narrowing, further narrowing of large arteries during hypocapnia might result in critical vascular narrowing and ischemia. A similar mechanism has been proposed for coronary arteries. In patients with Prinzmetal's angina, spasm of large coronary arteries may occur either in normal coronaries or at the site of mild stenosis and produce severe myocardial ischemia (10).

We suggest that the experiments described in this report have two important implications. First, in contrast to the traditional view, large arteries play an important role in physiologic regulation of cerebral blood flow. Second, in disease states that affect large cerebral arteries, regulation of cerebral blood flow may be impaired.

\section{ACKNOWLEDGMENTS}

We thank Donald Piegors, Judith Donnell, and Paul Gross for technical assistance, Dr. Leon Burmeister for assistance with statistical analyses, Oscar Lim for computer programming, Dr. James Ehrhardt for assistance with isotope separation, Patti Young for preparation of the manuscript, and Dr. Allyn Mark and Dr. Philip Schmid for critical review of the manuscript.

This work was supported by Research Career Development Awards HL-00041 and HL-00328, research grants HL-16066 and HL-20827, and program project grant HL-14388 from the National Heart and Lung Institute, and by research grant MRIS 3546 from the Veterans Administration.

\section{REFERENCES}

1. Bakay, L., and W. H. Sweet. 1952. Cervical and intracranial intraarterial pressure with and without vascular occlusion. Surg. Gynecol. Obst. 95: 67-75.

2. Shulman, K. 1965. Small artery and vein pressures in the subarachnoid space of the dog.J. Surg. Res. 5: 56-61.

3. Symon, L. 1967. A comparative study of middle cerebral pressure in dogs and macaques. J. Physiol. (Lond.). 191: 449-465.

4. Borras, A., M. S. Mendez, and A. Martinez. 1969. Opthalmic-brachial artery pressure ratio in man. Am. J. Opthalmol. 67: 684-688.

5. Kanzow, E., and D. Dieckhoff. 1969. On the location of the vascular resistance in the cerebral circulation. In Cerebral Blood Flow. M. Brock, C. Fieschi, D. H. Ingvar, L. A. Lassen, and K. Schurmann, editors. SpringerVerlag New York. 96-97.

6. Sharpiro, H. M., D. D. Stromberg, D. R. Lee, and C. A. Wiederhielm. 1971. Dynamic pressures in the pial arterial microcirculation. Am. J. Physiol. 22: 279-283.

7. Stromberg, D. D., and J. R. Fox. 1972. Pressures in the pial arterial microcirculation of the cat during changes in systemic arterial blood pressure. Circ. Res. 31: 229-238.

8. Magun, J. G. 1973. The effect of pharmacologically increased blood pressure on brain circulation. Z. Neurol. 204: 107-134.

9. Du Boulay, G., J. Edmonds-Seal, and T. Bostick. 1968. The effect of intermittent positive pressure ventilation upon the calibre of cerebral arteries in spasm following subarachnoid haemorrhage - a preliminary communication. Br. J. Radiol. 41: 46-48.

10. Endo, M., K. Hirosawa, N. Kaneko, K. Hase, Y. Inour, and S. Konno. 1976. Prinzmetal's variant angina. Coronary arteriogram and left ventriculogram during angina attack induced by methacholine. N. Engl. J. Med. 294: 252-255.

11. Rapela, C. E., and J. B. Martin. 1975. Reactivity of cerebral extra- and intraparenchymal vasculature to serotonin and vasodilator agents. In Blood Flow and Metabolism in the Brain. M. Harper, B. Jennett, D. Miller, and J. Rowan, editors. Church \& Livingston. 4.5-4.9.

12. Rudolph, A. M., and M. A. Heyman. 1967. The circulation of the fetus in utero: methods for studying distribution of blood flow, cardiac output, and organ flow. Circ. Res. 21: 163-184.

13. Heistad, D. D., M. L. Marcus, S. Sandberg, and F. M. Abboud. 1977. Effect of sympathetic nerve stimulation on cerebral blood flow and on large cerebral arteries of dogs. Circ. Res. 41: 342-350.

14. Wollschlaeger, G., and P. B. Wollschlaeger. 1974. The circle of Willis. In Radiology of the Skull and Brain: Angiography. Vol. 2. Bk. 2. T. H. Newton and D. G. Potts, editors. The C. V. Mosby Company, St. Louis, Mo. 11711201 .

15. Greenfield, J. C., Jr., and G. T. Tindall. 1968. Effect of norepinephrine, epinephrine, and angiotensin on blood 
flow in the internal carotid artery of man. J. Clin. Invest. 47: $1672-1684$.

16. Huntsberger, D. V., and P. E. Leaverton. 1970. Statistical Inference in the Biomedical Sciences. Allyn \& Bacon Inc., Boston.

17. Greenfield, J. C., Jr. 1969. Effect of serotonin on internal and external carotid artery blood flow in the baboon. Am. J. Physiol. 216: 50-55.

18. Kontos, H. A. 1975. Mechanisms of regulation of the cerebral micro-circulation. Stroke. 10: 7-12.

19. Raper, A. J., H. A. Kontos, and J. L. Patterson, Jr. 1971. Response of pial precapillary vessels to changes in arterial carbon dioxide tension. Circ. Res. 28: 518-523.

20. Fukasawa, H. 1969. Hemodynamic studies of cerebral arteries by means of mathematical analysis of arterial casts. Tohoku J. Exp. Med. 99: 255-268.

21. Heistad, D. D., M. L. Marcus, J. C. Ehrhardt, and F. M. Abboud. 1976. Effect of stimulation of carotid chemoreceptors on total and regional cerebral blood flow. Circ. Res. 38: 20-25.

22. Heistad, D. D., and M. L. Marcus. 1976. Total and regional cerebral blood flow during stimulation of carotid baroreceptors. Stroke. 7: 239-243.

23. Kontos, H. A., E. P. Wei, A. J. Raper, and J. L. Patterson.
1977. Local mechanism of $\mathrm{CO}_{2}$ action on cat pial arterioles. Stroke. 8: 226-229.

24. Abboud, F. M., and J. W. Eckstein. 1966. Comparative changes in segmental vascular resistance in response to nerve stimulation and to norepinephrine. Circ. Res. 18: $263-277$.

25. Abboud, F. M. 1968. Vascular responses to norepinephrine, angiotensin, vasopressin, and serotonin. Fed. Proc. 27: 1391-1395.

26. Irving, L., P. F. Scholander, and S. W. Grinnell. 1942. The regulation of arterial blood pressure in the seal during diving. Am. J. Physiol. 135: 557-566.

27. Heistad, D. D., F. M. Abboud, and J. W. Eckstein. 1968. Vasoconstrictor response to simulated diving in man. J. Appl. Physiol. 25: 542-549.

28. Nellis, S. M., A. J. Liedtke, R. Zelis, and L. Whitesell. 1977. Blood pressures in the microvasculature of the beating heart. Circulation. 56: III35. (Abstr.)

29. Fam, W. M., and M. McGregor. 1968. Effect of nitroglycerine and dipyridamole on regional coronary resistance. Circ. Res. 22: 649A. (Abstr.).

30. LaLone, B. J., S. M. Sullivan, and P. C. Johnson. 1977. Blood flow regulation in cat sartorius muscle. Fed. Proc. 36: 526. (Abstr.) 